\title{
Importance of Change Appraisal for Employee Well-being during Organizational Restructuring: Findings from the Finnish Paper Industry's Extensive Transition
}

\author{
Krista PAHKIN $^{1 *}$, Karina NIELSEN ${ }^{2}$, Ari VÄÄNÄNEN ${ }^{1}$, \\ Pauliina MATTILA-HOLAPPA ${ }^{1}$, Anneli LEPPÄNEN ${ }^{1}$ and Aki KOSKINEN ${ }^{1}$ \\ ${ }^{1}$ Finnish Institute of Occupational Health, Finland \\ ${ }^{2}$ University of East Anglia, Norwich Business School, Norwich Research Park, UK
}

Received February 13, 2014 and accepted May 22, 2014

Published online in J-STAGE June 27, 2014

\begin{abstract}
The global recession has forced the Finnish forest industry to carry out major restructuring activities. Employees have faced different kinds of restructuring, mainly aimed at reducing staff and production. Many studies have shown the negative consequences of restructuring on employee well-being by using negative, ill-health indicators. Our aim is to examine the extent to which change appraisal influences both the negative and positive aspects of work-related well-being among employees who continue working in the organization after the restructuring process. We also examine the role of different actors (top management, immediate supervisor, employees themselves) in how the change is appraised. The study investigated blue-collar employees working in the Finnish forest industry during a period of extensive transition (2008-2009). All six participating factories underwent restructuring between baseline and the follow-up survey $(n=369)$. After adjustment for gender, age and baseline well-being, negative change appraisal increased the risk of experiencing more stress and less work enjoyment. Negative change appraisals thus also damaged the positive, motivational aspects of employee well-being. The results showed the importance of offering employees the opportunity to participate in the planning of changes related to their work as regards positive change appraisal.
\end{abstract}

Key words: Change appraisal, Change management, Affective well-being, Restructuring, Employees

\section{Introduction}

In order to survive and succeed in modern business life, organizations are forced to carry out different kinds of restructuring. It is likely that the majority of employees will

*To whom correspondence should be addressed. E-mail: krista.pahkin@ttl.fi

(C)2014 National Institute of Occupational Safety and Health face organizational restructuring at some point during their working careers. Many studies have shown that restructuring can have a detrimental effect on the health ${ }^{1)}$ and mental well-being of employees ${ }^{2)}$ who continue working in the organizations after restructuring. Furthermore, previous research ${ }^{3)}$ has identified several mechanisms through which the restructing effects to well-being. One of these mechanisims seems to be change appraisal, i.e. whether employees perceive the changes as positive or negative. Surprisingly few studies have focused on how the ap- 
praisal of restructuring process influences the affective well-being ${ }^{4}$, of employees experiencing organizational upheaval, and how positive appraisals could be enhanced. In this paper, we will concentrate on the change appraisal of employees who go through the whole restructuring process in their workplace, the so-called survivors ${ }^{5)}$ of the restructuring, and to the way in which the restructuring process was managed at their workplace.

According to cogntive appraisal theory ${ }^{6}$, the way in which people appraise the situations they find themselves in influences how they react to these situations. This acts as a trigger to their well-being. Employees categorize features of their environment according to their relevance to well-being, potential to harm well-being and lead to stress, or as a challenge that may lead to positive states of well-being, such as enjoyment and job satisfaction. Organizational restructuring can be a potentially stressful situation, since employees are, for example, unsure of the consequences of the restructuring; whether or not they will lose their job or if they will be able to handle the possible changes to their job tasks ${ }^{3)}$. Monat and Lazarus ${ }^{7)}$ have stated that a negative organizational change, such as the downsizing activities carried out in our study, is likely to be experienced as a potential threat that may exceed the adaptive resources of the employee. However, restructuring may also be perceived as a positive challenge, because it may for example create the chance to influence the future of the organization ${ }^{3)}$ or it may create opportunities for promotions ${ }^{8)}$.

Earlier research focusing on the associations between organizational restructuring and employee health and mental well-being has mainly used negative indicators, such as emotional exhaustion, mental disorders, mortality, sickness absence, stress or use of psychotropic drugs ${ }^{9-16)}$. The approach has been predominantly disorder-orientated: Health or well-being has been seen as absence of diseases/ disorders or symptoms of strain and an employee is healthy or feeling well when she/he is not ill or has no symptoms of strain. Research focusing on more positive indicators of well-being have used measures of job satisfaction $^{17,18)}$, job commitment ${ }^{19)}$ or organizational trust ${ }^{20)}$. Often intention to turnover has been used as a counter part for example to job satisfaction ${ }^{21,22)}$. However, research combining these two approaches of employee well-being, ill-health vs. positive state ${ }^{23)}$, in the context of organizational restructuring is more rare.

Research has also focused more on negative change appraisal, the role of emotions and coping strategies in the context of organizational restructuring and used nega- tive indicators of well-being such as sick time used, quit intention or psychiatric morbidity $\left.{ }^{24}, 25\right)$. However, the cognitive approach by Lazarus ${ }^{6)}$ and other views, such as the challenge-hindrance framework ${ }^{26)}$, suggest that changes may have positive consequences for individual employees, and thus for their well-being, if appraised as a positive challenge. There is already some evidence that the effects of restructuring on the health and mental wellbeing of employees differ based on their change appraisal. For example, a self-assessed decline in position (negative appraisal) has been linked to increased exhaustion, cynicism, stress and deterioration of work ability, whereas self-assessed improvement to one's job position (positive appraisal) has been associated with higher task autonomy and support from top management which in turn has favorable effects on employee well-being ${ }^{3)}$. It is thus important from the perspective of an individual's well-being to explore whether restructuring situations are appraised as good or bad.

In this longitudinal study, we examine both the negative and positive change appraisal and explore its association with both negative and positive indicators of affective well-being. The aim was to identify specific subjective outcomes of the organizational restructuring for employees' well-being in a context of severe structural change in the sector of employment under study. Our first hypothesis is that negative change appraisal is related to lower affective well-being, measured using negative and positive indicators (Hypothesis 1).

In recent years, interest has increased in how organizations manage restructuring processes to ensure employee well-being. The resources made available to staff (situational, external coping resources ${ }^{27,28)}$ ) may impact the way in which employees appraise the changes and thus also their own well-being. According to Westgaard and Winkel $^{29)}$, key factors of well-managed restructuring processes are employee participation, information and communication, management style, organizational and social support, and perceived justice. Similar kinds of key factors have also been highlighted in other studies ${ }^{3,30-34)}$. Top managent is seen to play an important role during restructuring process ${ }^{3)}$.

What is problematic is that the recommendation mentioned above deals with different kinds of actions: some of them focus on specific actors, such as management, but some of them are more concerned with the way in which they act and the quality of these actions, such as open, honest communication. To clarify the role of these different situational coping resources, we explore the impact of 
different actors (top management, immediate supervisors or line-managers, employees themselves) on the way in which employees experience the restructuring process; their change appraisal. Our second hypothesis is that top management plays the strongest role in influencing employees' change appraisals (Hypothesis 2).

\section{Participants and Methods}

\section{Study context and procedure}

The Finnish Forest Industries (employer association) and the Finnish Paper Workers' Union (employees association) asked the Finnish Institute of Occupational Health (FIOH) to conduct a project that would focus on the wellbeing of employees, since the sector had the second highest rate of sickness absence among industrial sectors ${ }^{35)}$. Eight production facilities from four different companies took part in this project, which was called 'Promoting occupational well-being and managing sickness absences in the Finnish paper industry ${ }^{36)}$. It was carried out in 2008-2009.

We obtained the approval of FIOH's Ethics Committee for the study, and in spring 2008 (baseline, $\mathrm{T}^{1}$ ), a questionnaire was sent to all blue-collar employees (response rate was $52 \%, \mathrm{n}=1,955$ ) at their workplace. Responding to the questionnaire was voluntary and anonymity was assured. However, together with the questionnaire, we requested written permission from the participants to obtain their sickness absence records. This permission, when obtained, made it possible to identify the respondents, but confidentiality was guaranteed and we explained in detail the procedure for safeguarding anonymity to them. For the longitudinal design of the study this meant that longitudinal data could only be collected from those employees who completed both surveys and who at both times gave written permission to access their sickness absence records. This approach was selected because of the sensitivity of the studied phenomenon.

The consequences of the global economic recession started to influence the sector under study in the autumn of 2008, and the entire Finnish forest industry faced productivity problems. The recession also affected the participating companies and different kinds of restructuring activities were initiated, such as outsourcing, temporal layoffs, redundancies, and the closing down of units. As a consequence, the number of blue-collar employees decreased by $28 \%$ in the participating units within two years ${ }^{37)}$. A year after the recession started, in the autumn of $2009\left(\mathrm{~T}^{2}\right)$, we carried out a follow-up survey (response rate $48 \%, n=1,518)$. At this time, restructuring activities were already over in the participating production facilities. For the follow-up survey, we shortened and modified the original questionnaire, and added questions related to, for example, the way in which the restructuring process was managed.

\section{Participants}

Of the original participating companies, six production facilities (from four companies) were selected for this study. Two facilities were excluded because one was totally closed down and follow-up information was thus not available, and in the other, downsizing activities were on-going during the first survey, so baseline information was not available. For the selected production facilities, restructuring mostly meant different kinds of downsizing activities.

All participants $(\mathrm{n}=369)$ were blue-collar employees, most of them were men $(89 \%)$. The mean age at $\mathrm{T}^{2}$ was 43.0 ( $\mathrm{sd} 9.3$ ). The average time that they had worked at the company was $20.0 \mathrm{yr}$, and in the same task $10.2 \mathrm{yr}$. The participants were representative of the whole study population in terms of average age, gender distribution, and average time in the company and the same task.

\section{Measures}

Change appraisal

As has been suggested ${ }^{38)}$ we focused on the employees' own evaluation of the personal consequences of the restructuring and asked at $\mathrm{T}^{2}$ : "When you think of all the changes that have taken place in your work during the last year, how would you describe the situation from your own standpoint?" The types of restructuring activities carried out were introduced separately before this question. Participants were asked to indicate their answer on a fivepoint scale ( 1 "Changes have mostly been negative" to 5 "Changes have mostly been positive").

\section{Appraisal of change management}

Recommendations of activities to be carried out during a restructuring process emphasize the roles of different actors and their actions. In the study, we evaluated the role of top management, immediate supervisors, and the employees themselves by looking at their actions during the restructuring process. These actions were evaluated at $\mathrm{T}^{2}$, a year after the restructuring process began in their organizations.

When evaluating the role of top management or immediate supervisors, participants were asked to separately es- 
Table 1. The content and the reliability of the sum scales

\begin{tabular}{|c|c|c|}
\hline & Question/s & Alpha $^{\mathrm{a}}$ \\
\hline $\begin{array}{l}\text { Actions of top } \\
\text { management }\end{array}$ & $\begin{array}{l}\text { Management has informed clearly about the goals of change. } \\
\text { Management has informed about the current state of change progress. } \\
\text { Management has taken into account personnel status and views while making decisions. } \\
\text { Management has made sure, that decisions have been implemented equally. } \\
\text { Management has made sure that there are sufficient change support services for whole personnel. } \\
\text { Management has actively solved problems that have emerged during change process. }\end{array}$ & 0.91 \\
\hline $\begin{array}{l}\text { Actions of immediate } \\
\text { superior }\end{array}$ & $\begin{array}{l}\text { My immediate superior has informed clearly about the goals of change. } \\
\text { My immediate superior has informed about the current state of change progress. } \\
\text { My immediate superior has discussed with his/her subordinates about the matters related with change. } \\
\text { My immediate superior has made sure, that individual preferences have not had disturbing impact on } \\
\text { his/her decisions. } \\
\text { My immediate superior has actively solved problems that have emerged during change process. }\end{array}$ & 0.93 \\
\hline Work enjoyment & $\begin{array}{l}\text { How satisfied are you with your current job? } \\
\text { How often you are enthusiastic about your job? } \\
\text { How often you are immersed in your work? }\end{array}$ & 0.89 \\
\hline
\end{tabular}

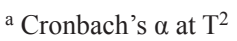

timate how these two groups had acted when planning and implementing the changes (Table 1). The statements that they had to evaluate were targeted towards communication, support and the justice of decisions made. The quality of actions was evaluated on a five-point scale ( $1=$ "very poorly" to 5 "very well"). The questions were developed for the study on the basis of the interviews carried out in the project and the literature available at the time ${ }^{39)}$.

We evaluated the employee's own role by asking: "In your opinion, when changes related to your work have been planned at your workplace, have you been able to sufficiently participate in the planning?" Participants were asked to indicate their answer on a five-point scale (1 "completely insufficiently" to 5 "completely sufficiently").

\section{Employee well-being}

This study addressed well-being from the perspective of affective well-being ${ }^{4}$, but from two different aspects based on the view of positive psychology ${ }^{23)}$ : as negative (feelings of work-related stress) and as positive (feeling of work enjoyment) well-being.

Feelings of stress was measured at $\mathrm{T}^{1}$ and $\mathrm{T}^{2}$ with a single question: "Stress is defined as a situation in which a person feels tense, restless, nervous or anxious, or is unable to sleep at night because of a constantly troubled mind. Do you feel this kind of stress?" Participants were asked to indicate their answers on a five-point scale (1 "very rarely" to 5 "very often"). The item was from the Occupational Stress Questionnaire (OSQ) ${ }^{40)}$ and has previously been found to be reliable ${ }^{41,42)}$.

We used a feelings of work enjoyment sum scale at $\mathrm{T}^{1}$ and $\mathrm{T}^{2}$ as an overall measure of positive well-being ${ }^{43)}$. The questions (Table 1) measured job satisfaction ${ }^{44)}$, enthusiasm and absorption ${ }^{45)}$. Participants were asked to indicate their answer on a five-point scale ( 1 "very unsatisfied/ rarely" to 5 "very satisfied/often").

\section{Background characteristics}

The questionnaire requested data on age and gender.

\section{Statistical analyses}

First, we assessed the internal consistency of the sum scales formed with factor analyses and Cronbach's $\alpha$ (Table 1). The factor analyses gave a one-factor solution for the actions of both the top management and the immediate supervisors (as well as for work enjoyment).

To test Hypotheses 1 we examined the associations between the change appraisal and study variables (measures of affective well-being) by cross-tabulations and $\chi^{2}$ tests (Table 2). To analyze the longitudinal association between the change appraisal and well-being, we applied logistic regression analysis. The outcome measure was dichotomized (not at all + some vs. a lot). Odds ratios (OR) and their $95 \%$ confidence intervals (CIs) were calculated using the positive category (medium + positive change appraisal) as a reference for both the unadjusted and adjusted model (Table 3). The model was adjusted for gender, age and affective well-being (feelings of stress/work enjoyment) at baseline. In addition, we tested the moderating effects of change appraisal on the level of well-being by interaction terms (change appraisal*feelings of stress/work enjoyment). 
Table 2. Study variables according to change appraisal at $\mathbf{T}^{2}$

\begin{tabular}{|c|c|c|c|c|c|}
\hline \multirow[b]{3}{*}{ Feelings of stress } & \multicolumn{4}{|c|}{ Change appraisal at $\mathrm{T}^{2}$} & \multirow{3}{*}{$\begin{array}{c}p \text {-value } \\
<0.001\end{array}$} \\
\hline & \multicolumn{2}{|c|}{ Med/Positive } & \multicolumn{2}{|c|}{ Negative } & \\
\hline & $\mathrm{n}$ & $\%$ & $\mathrm{n}$ & $\%$ & \\
\hline Yes (a lot) & 16 & $6 \%$ & 35 & $19 \%$ & \\
\hline No (not at all, some) & 245 & $94 \%$ & 150 & $81 \%$ & \\
\hline Work enjoyment & & & & & $<0.001$ \\
\hline No (not at all, some) & 68 & $26 \%$ & 117 & $63 \%$ & \\
\hline Yes (a lot) & 193 & $74 \%$ & 70 & $37 \%$ & \\
\hline Top management & & & & & $<0.001$ \\
\hline Poor & 63 & $24 \%$ & 95 & $51 \%$ & \\
\hline Medium & 114 & $43 \%$ & 67 & $36 \%$ & \\
\hline Good & 85 & $32 \%$ & 25 & $13 \%$ & \\
\hline Immediate supervisor & & & & & 0.002 \\
\hline Poor & 64 & $25 \%$ & 72 & $39 \%$ & \\
\hline Medium & 119 & $46 \%$ & 82 & $44 \%$ & \\
\hline Good & 76 & $29 \%$ & 33 & $18 \%$ & \\
\hline Own participation & & & & & $<0.001$ \\
\hline Poor & 99 & $38 \%$ & 126 & $67 \%$ & \\
\hline Medium & 95 & $37 \%$ & 44 & $24 \%$ & \\
\hline Good & 64 & $25 \%$ & 17 & $9 \%$ & \\
\hline
\end{tabular}

Table 3. Unadjusted and adjusted odds ratios (OR) and their $95 \%$ confidence intervals (95\% CI) of feeling more stress or less work enjoyment according to change appraisal

\begin{tabular}{cccc}
\hline Level of symptoms & $\mathrm{n}$ (cases) & $\begin{array}{c}\text { Unadjusted } \\
\text { OR }(95 \% \mathrm{CI})\end{array}$ & $\begin{array}{c}\text { Adjusted } \\
\text { OR }(95 \% \mathrm{CI})^{\mathrm{a}}\end{array}$ \\
\hline Change appraisal & Feelings of stress & & \\
Med/Good & $261(16)$ & 1.00 (ref.) & 1.00 (ref.) \\
Bad & $185(35)$ & $3.57(1.80-7.10)$ & $3.44(1.71-6.92)$ \\
Change appraisal & Work enjoyment ${ }^{\mathrm{b}}$ & & \\
Med/Good & $187(70)$ & 1.00 (ref.) & 1.00 (ref.) \\
Bad & $261(193)$ & $5.13(3.16-8.32)$ & $5.14(3.17-8.35)$ \\
\hline
\end{tabular}

OR: Odds ratio, CI: confidence interval. aAdjusted for gender, age and feelings of stress/work enjoyment at T1. ${ }^{b}$ Work enjoyment scales is revered and the risk of experiencing less work enjoyment is calculated.

We also applied logistic regression analysis in order to test Hypotheses 2. The outcome measure, change appraisal, was dichotomized (medium + positive vs. negative), and the models were adjusted for gender and age. The explanatory power of each of the models was also calculated. To test Hypothesis 2, we examined, in a cross-sectional setting, the association between the different actors (top management, immediate supervisors and employees themselves) and the risk of negative change appraisal (Table 4). All the analyses were conducted using the SAS V.9.2 statistical software package.

\section{Results}

At $\mathrm{T}^{1}$, the average level of feelings of stress was 2.13 (sd 0.92 ) and a year later 2.23 (sd 0.98) (repeated measures $t$-test, $p=0.04$ ). The level of work enjoyment was 3.56 (sd $0.98)$ at $\mathrm{T}^{1}$ and $3.59\left(\mathrm{sd} \mathrm{0.89)}\right.$ ) at $\mathrm{T}^{2}$ (repeated measures $t$-test, $p=0.47$ ). Our first hypothesis was related to change appraisal and its effect on affective well-being. We predicted that negative change appraisal is related to lower affective well-being. The results show that the level of affective well-being, in both its negative and the positive state, was lower among employees with negative change appraisal at $\mathrm{T}^{2}$ (Table 2). 
Table 4. Role of different actors in change appraisal

\begin{tabular}{|c|c|c|c|c|c|}
\hline & & \multicolumn{4}{|c|}{ Change appraisal } \\
\hline & & $\begin{array}{c}\text { Model } 1 \\
\text { OR }(95 \% \text { CI })\end{array}$ & $\begin{array}{c}\text { Model } 1 \\
\text { OR }(95 \% \text { CI })\end{array}$ & $\begin{array}{c}\text { Model } 1 \\
\text { OR }(95 \% \mathrm{CI})\end{array}$ & $\begin{array}{c}\text { Model } 2 \\
\text { OR }(95 \% \mathrm{CI})\end{array}$ \\
\hline \multirow[t]{3}{*}{ Top management } & Good & 1.00 & & & 1.00 \\
\hline & Medium & $1.95(1.13-3.35)$ & & & $1.65(0.89-3.05)$ \\
\hline & Bad & $5.26(3.03-9.15)$ & & & $3.94(2.03-7.67)$ \\
\hline \multirow[t]{3}{*}{ Immediate supervisor } & Good & & 1.00 & & 1.00 \\
\hline & Medium & & $1.54(0.93-2.53)$ & & $0.69(0.38-1.28)$ \\
\hline & $\mathrm{Bad}$ & & $2.72(1.59-4.65)$ & & $0.73(0.36-1.48)$ \\
\hline \multirow[t]{4}{*}{ Own participation } & Good & & & 1.00 & 1.00 \\
\hline & Medium & & & $1.72(0.90-3.29)$ & $1.56(0.79-3.09)$ \\
\hline & $\mathrm{Bad}$ & & & $4.93(2.71-8.97)$ & $3.76(1.92-7.36)$ \\
\hline & R-Square & 0.09 & 0.04 & 0.09 & 0.14 \\
\hline
\end{tabular}

OR: Odds ratio, CI: confidence interval. Adjusted for gender and age

Compared with their counterparts, the employees who experienced the restructuring negatively were at a considerably higher risk of having lower affective well-being after the restructuring process. The risk of feeling more stress and enjoying work less was also higher among employees who experienced the restructuring process negatively; those who had negative change appraisal (Table 3). The data thus supported our hypothesis. In addition, we tested whether the change appraisal could also moderate the previously noticed increase in feelings of stress. However we found no significant interactions $(p=0.68)$.

Our next step was to examine the role of different actors (top management, immediate supervisors, employees themselves) in the way in which employees appraised the restructuring process. We hypothesized that top management and its action would be the key factor influencing employees' change appraisal. The results show that each of the studied actors were related to the change appraisal (Table 4). However, it was employees' poor opportunities to participate in the planning of the restructuring which was particularly linked to negative change appraisal in both models. One's own participation and the role of top management had the strongest explanatory power in the employees' change appraisal. The role of immediate supervisors became non-significant in the model that included all explanatory factors (Model 2). Together these factors explained $14 \%$ of the employees' change appraisal.

\section{Discussion}

The presented study examined the consequences of restructuring on employees' well-being. Although this in itself is not new, the study added to the current knowledge in two ways. We focused on employees who go through the whole restructuring process in their workplace from the announcement of the forthcoming changes to their implementation. First, the attention was on their own views of the consequences of the restruturing process (negative vs. positive change appraisal) and its associations to their well-being. Previous restructuring research has mainly concentrated on the negative state of well-being and neglected the positive, motivational state, but in our study both aspects were taken into consideration simultaneously. Second, the attention of the study was on the situational, external coping resources available to employees, meaning the actual change management activities provided by the organization.

\section{Detrimental effects of negative change appraisal}

In line with our hypotheses, we learned that change appraisal does indeed affect employee well-being. This result is in line with the cogntive appraisal theory of Lazarus and Folkman ${ }^{6}$ and the view of the challenge-hindrance framework $^{26)}$. What is important is that we did not study the consequences of change appraisal only in the light of strain and other outcomes, such as performance, but took a more comprehensive view of well-being, as has been suggested $^{43)}$, and also used positive indicators of affective well-being. The first contribution of our study is thus its result that experiencing restructuring processes negatively does not only increase strain or ill-health at work, it also damages the positive, motivational aspects of employee well-being ${ }^{23)}$.

Important role of employee participation in the process

Our first finding showed that whether the situation is 
interpreted negatively (as a threat) or positively (as a challenge) is important. The second contribution of the study is that we explored the roles of different actors (top management, immediate supervisors, employees themselves) in relation to employees' appraisals of restructuring. We paid attention to the roles of those who been labelled as the key actors in a well-managed restructuring process ${ }^{29}$. We hypothesed that the top management would be the most important actor. However, the results revealed that the role of employees' own opportunities to participate was slightly greater than the role of top management. The role of immediate supervisors was also important, but diminished in the overall model.

In our study we only focused on employees' opportunities to participate in the planning of restructuring from their own viewpoint. The result, i.e., that the more an employee is able to participate in the planning of changes related to their work during the restructuring process, the more positive a view they have of the change, is in line with Lazarus, ${ }^{46)}$ view that it is the appraisal of whether or not a person can do anything to change the given situation that effects the way in which they cope with it. The result also supports the earlier recommendations that employees should be involved in planning and carrying out restructuring processes ${ }^{3,30)}$. Our result also supports the findings of intervention research, which highlights the importance of employees' own activity and participation (participatory action approach) in implementing organizational development programs ${ }^{31,47)}$.

In practice, the restructuring process is, however, very much led by the top management. This is understandable, since the reason behind organizational restructuring can often be found in factors outside the organization, such as changes in inter-/national market competition, the opening of new markets, or cuts in expenses, and it is the top management of the organization that decides how these challenges are met. The extent to which employees can in practice participate in the planning and implementing of restructuring processes is also in the hands of the top management. Therefore, we tested the correlation between employees' opportunities to participate and top management actions, and found them to be connected ( $\mathrm{r}=0.42$, $p<0.01$ ). For a successful restructuring process, our results suggest that the process should be viewed and managed as any other organizational development program carried out at the workplace, and therefore employees should be involved as much as possible.

Another interesting factor was the results concerning the role of immediate supervisors in the restructuring process.
There may be several explanations as to why their role was not as important in our study as expected. An earlier study ${ }^{48)}$ has shown that pre-change supervisor's support was not associated with the health of blue-collar employees. As our study focused only on blue-collar employees, this may have diminshed the importance of supervisor support. If the study had included white-collar employees, the results may have been different. The actions of top management and immediate supervisors were also strongly connected to each other $(\mathrm{r}=0.60, p<0.01)$. This is not suprising, since in practice, without support from top management, immediate supervisors have very limited "tools" for informing and supporting their employees or for justifying the decisions carried out in the organization during restructuring. Thus, as has been recommended ${ }^{3)}$, immediate supervisors are important actors during the restructuring process, since they can influence the way in which employees interpret restructuring: its effects on them during the process, and on their job and its security.

\section{Methodological aspects}

Although the study has several limitations, it also has strengths. One of the main strengths was that the study was partly carried out in a longitudinal design. We concentrated on the consequences of the appraisals of the restructuring process for the well-being of employees who went through the whole restructuring process, from the announcement of the forthcoming changes to their implementation. Paying attention to employees' well-being is important, since they are the ones who will ultimately be responsible for meeting the production-oriented goals of restructuring.

We asked employees' to evaluate the personal consequences of the restructuring as has been suggested ${ }^{38)}$, and asked if they experienced these consequences as positive or negative. As our study relies on self-reports, common method bias may present a threat to our results. It is possible that some participants may have recalled the past events over-optimistically ${ }^{49}$ ) or some of the negative effects of the restructuring may have been over by the time the post-change data collection was carried out. However, it is most likely that participants fairly accurately appraise their overall experience of restructuring, since the effect of restructuring on their tasks, for example, was presumably realized at the time of the data collection. Subjective appraisals have been found ${ }^{50)}$ to play a crucial role in determining the health and well-being of employees.

However, the study does not address the reasons behind the appraisal; why the situation is actually viewed as a 
positive challenge or hindrance ${ }^{6)}$ or how this personal response is determined. It does not really look at the role of the psychological factors that employees bring to the scenario, such as personality traits, expectations, outlook of life, or resilience ${ }^{51)}$. For example, generalized optimism has been found to be associated with expectations of success and the use of positive thinking as a coping strategy during organizational downsizing ${ }^{17)}$.

We also used two distinctive indicators of well-being, which were measured at both $\mathrm{T}^{1}$ and $\mathrm{T}^{2}$. Well-being is often measured by using negative indicators (e.g. sickness absence), but since it is not only the absence of illness $^{23,43,52)}$ we also used a positive indicator of wellbeing. According to Warr ${ }^{4}$ the positive side of affective well-being includes feeling relaxed, cheerful, enthusiastic, and optimistic. To be able to capture more feelings related to affective well-being, we formed the sum scale of work enjoyment on the basis of questions related to job satisfaction ${ }^{44)}$, enthusiasm and absorption, modified from the work engagement scale ${ }^{45)}$, rather than using only the single item measure of job satisfaction ${ }^{44)}$. Although the stress variable (negative indicator of well-being) used in the study was a single variable, it has been widely used in other Finnish studies, and has been found to be reliable and acceptable for use ${ }^{41,42)}$. The selected approach made it possible to obtain a wider view of the consequences of restructuring for employees' well-being compared to that of earlier studies of restructuring.

The questionnaire also included specific questions aimed to determine how the restructuring process was handled: by whom and through what kinds of actions. Even though the questions were only introduced at $\mathrm{T}^{2}$, the respondents were looking back at the restructuring process that they had gone through during the past year. We studied how much information and support employees felt they received from the top management and their immediate supervisors during the restructuring process, and if actions were considered fair (justice). We also had information on the extent to which employees felt they had been able to participate in the planning of the changes related to their own work as a result of restructuring. We were thus able to simultaneously measure the role of the actors who are believed to be behind well-managed, sound restructuring processes $^{3,32)}$.

It is also possible that the consequences are more severe than our results show. The sample size of the longitudinal dataset was relatively small. Our study population focused only on those employees who remained working in the organization after the restructuring process, who at both times had given their permission to use their sickness absence records, and who had answered the follow-up survey after a difficult period. All this may indicate that they represent a group of employees whose personal and social resources may be relatively good (i.e. the healthy worker effect ${ }^{53)}$ ). However, the sample was representative and their well-being was clearly affected by the restructuring process and the way in which it was managed.

Like Tvedt et al. ${ }^{54)}$, we were interested in the overall effect of restructuring, and did not separate different restructuring activities and their effects. The reason for this approach was practical, since in half of the studied production facilities, different types of restructuring activities were carried out simultaneously and it was thus impossible to separate each restructuring activity's own effect. However, what was common to our cases was that in each one, some sort of downsizing activities were carried out, targeting either the number of employees or production.

When considering the findings, it is important to remember that the data was collected during a time when the whole Finnish forest industry was facing economic difficulties. The majority of the participants worked at industrial plants in small and often remote communities, where their employer was one of the major employers in that area. Therefore, the likelihood of finding a new, similar job, if dismissed, may have been fairly low for the majority of the employees. All this might have caused stronger reactions among these employees than those in a situation in which the future of the whole sector was not under threat. Since the severity of the situation in the participating production facilities varied regardless of whether or not they included redundancies, it is also possible that the efforts made in managing the restructuring processes differ. It is most likely that the actions taken in cases in which the employer is forced to make employees redundant differ greatly from those taken in situations in which only temporary layoffs are carried out. Given the small longitudinal sample size in our study, we were unable to account for the severity of the changes carried out in the organizations in our analyses.

Finally, the sample of the study was strongly maledominated and restricted to the so called blue-collar employees in the paper industry. Although there are undisputed benefits to using a homogeneous sample; for example the intensive study of a certain target group, the findings do not therefore necessary apply to, for example, female-dominated fields of working life. 


\section{Concluding remarks}

Research on restructuring and changes at work should more clearly discuss the different contexts and types of change, and their consequences. The severity of organizational restructuring should be taken into account not only in the form of the risk they may pose to the continuity of work (threat approach) ${ }^{55}$, but also in the sense of how much they actually change the work and its content, and thus what kind of challenges they create for employees' (challenge approach).

Based on our findings that negative change appraisal affects both aspects of affective well-being, research on restructuring could also benefit from using, for example, the job demands-resources (JD-R) model ${ }^{56)}$. It would also be important to obtain a wider view of resources that could support the motivational state of well-being ${ }^{57)}$ when employees face organizational restructuring processes during their working career. More information is also needed on the long-term effects of change appraisal on the well-being, behavior and success of both individuals and organizations. In addition, since employees may experience several restructuring processes during their working careers, the effect of earlier change appraisals in the context of the next restructuring process they face should also be studied.

Future studies should pay attention to how much effort is actually put into the management of the restructuring process in an organization. The whole restructuring process, its different stages ${ }^{58)}$, as well as the role of different actors and their actions should also be better taken into account in research designs in order to determine how the management of restructuring processes could evoke positive change appraisal and thus support the well-being of employees.

The present research yields some important implications for managers, supervisors and human resource experts carrying out restructuring processes in organizations. We were able to show the influence of change appraisal, i.e. the way in which the restructuring process is experienced, on employees' well-being. Poor change appraisal did not only increase strain or ill-health at work, it also threated the positive, motivational aspects of employees' wellbeing. Keeping employees motivated to work is crucial so that the organization can reach the primary, productionrelated goals of restructuring. For example, work engagement, as an indicator of positive well-being, has been found to be associated with productivity ${ }^{59)}$.

Our findings show that employees' own opportunites to participate and support from top management, without understating the role of immediate supervisors, are important factors, as they are likely to influence the way in which employees experience changes. Paying attention to the way in which the change process is managed in an organization is thus crucial.

\section{Acknowledgement}

This study was financially supported by the Finnish Work Environment Fund (109395 and 107240).

\section{References}

1) Ferrie JE, Westerlund H, Virtanen M, Vahtera J, Kivimäki M (2008) Flexible labor markets and employee health. SJWEH 6, 98-110.

2) Bamberger $S G$, Vinding $A L$, Larsen $A$, Nielsen $P$, Fonager K, Nielsen RN, Ryom P, Omland Ø (2012) Impact of organisational change on mental health: a systematic review. Occup Environ Med 69, 592-8. [Medline] [CrossRef]

3) Wiezer N, Nielsen K, Pahkin K, Widerszal-Bazyl M, de Jong T, Mattila-Holappa P, Mockallo Z (2011) Exploring the link between restructuring and employee well-being, Central Institute for Labour Protection - National Research Institute, Warsaw.

4) Warr P (1987) Work, Unemployement and Mental Health, Oxford University Press, Oxford.

5) Noer D (1993) Healing the wounds: Overcoming the trauma of layoffs and revitalizing downsized organisations, Jossey-Bass, San Francisco.

6) Lazarus RS, Folkman S (1984) Stress, appraisal and coping, Springer Publications, New York.

7) Monat A, Lazarus RS (1985) Stress and coping: an anthology 2nd Ed., Columbia Universtity Press, New York.

8) Armstrong-Stassen M (2003) Job transfer during organizational downsizing. Group Organ Manage 28, 392-415. [CrossRef]

9) Geuskens GA, Koppes LLJ, van den Bossche SNJ, Joling CI (2012) Enterprise restructuring and the health of employees: a cohort study. J Occup Environ Med 54, 4-9. [Medline] [CrossRef]

10) Bourbonnais R, Brisson C, Vézina M, Masse B, Blanchette C (2005) Psychosocial work environment and certified sick leave among nurses during organizational changes and downsizing. Ind Relat 60, 483-507.

11) Kivimäki M, Honkonen T, Wahlbeck K, Elovainio M, Pentti J, Klaukka T, Virtanen M, Vahtera J (2007) Organisational downsizing and increased use of psychotropic drugs among employees who remain in employment. J Epidemiol Community Health 61, 154-8. [Medline] [CrossRef]

12) Vahtera J, Kivimäki M, Pentti J (1997) Effect of organisational downsizing on health of employees. Lancet 
350, 1124-8. [Medline] [CrossRef]

13) Vahtera J, Kivimäki M, Pentti J, Linna A, Virtanen M, Virtanen P, Ferrie JE (2004) Organisational downsizing, sickness absence, and mortality: 10-town prospective cohort study. BMJ 328, 555-60. [Medline] [CrossRef]

14) Wang J, Patten S, Currie S, Sareen J, Schmitz N (2012) Business mergers and acquisitions and the risk of mental disorders: a population-based study. Occup Environ Med 69, 569-73. [Medline] [CrossRef]

15) Quinlan M, Bohle P (2009) Overstretched and unreciprocated commitment: reviewing research on the occupational health and safety effects of downsizing and job insecurity. Int J Health Serv 39, 1-44. [Medline] [CrossRef]

16) Woodward CA, Shannon HS, Lendrum B, Brown J, McIntosh J, Cunningham C (2000) Predictors of job stress and satisfaction among hospital workers during re-engineering: differences by extent of supervisory responsibilities. Healthc Manage Forum 13, 29-35. [Medline] [CrossRef]

17) Armstrong-Stassen M, Schlosser F (2008) Taking a positive approach to organizational downsizing. Can J Adm Sci 25, 93-106. [CrossRef]

18) Bordia P, Hunt E, Paulsen N, Tourish D, DiFonzo N (2004) Uncertainty during organizational change: is it all about control? Eur J Work Organ Psychol 13, 345-65. [CrossRef]

19) Allen TD, Freeman DM, Russell JEA, Reizenstein RC, Rentz JO (2001) Survivor reactions to organisational downsizing: does time ease the pain? J Occup Organ Psychol 74, 145-64. [CrossRef]

20) Armstrong-Stassen M (2002) Designated redundant but escaping lay-off: a special group of lay-off survivors. J Occup Organ Psychol 75, 1-13. [CrossRef]

21) Armstrong-Stassen M, Cameron SJ, Mantler J, Horsburgh ME (2001) The impact of hospital amalgamation on the job attitudes of nurses. Can J Adm Sci 18, 149-62. [CrossRef]

22) Wanberg CR, Banas JT (2000) Predictors and outcomes of openness to changes in a reorganizing workplace. J Appl Psychol 85, 132-42. [Medline] [CrossRef]

23) Seligman MEP, Csikszentmihalyi M (2000) Positive psychology. An introduction. Am Psychol 55, 5-14. [Medline] [CrossRef]

24) Fugate M, Kinicki AJ, Prussia GE (2008) Employee coping with organizational change: an examination of alternative theoretical perspectives and models. Person Psychol 61, 1-36. [CrossRef]

25) Väänänen A, Ahola K, Koskinen A, Pahkin K, Kouvonen A (2011) Organizational merger and psychiatric morbidity: a prospective study in a changing work organization. $\mathrm{J}$ Epidemiol Community Health 65, 682-7. [CrossRef]

26) Cavanaugh MA, Boswell WR, Roehling MV, Boudreau JW (2000) An empirical examination of self-reported work stress among U.S. managers. J Appl Psychol 85, 65-74. [Medline] [CrossRef]

27) Scheck CL, Kinicki AJ (2000) Identifying the antecedents of coping with an organizational acquisition: a structural assessment. J Organ Behav 21, 627-48. [CrossRef]

28) Shaw JB, Fields MW, Thacker JW, Fisher CD (1993) The availability of personal and external coping resources: their impact on job stress and employee attitudes during organizational restructuring. Work Stress 7, 229-46. [CrossRef]

29) Westgaard RH, Winkel J (2011) Occupational musculoskeletal and mental health: Significance of rationalization and opportunities to create sustainable production systems-A systematic review. Appl Ergon 42, 261-96. [Medline] [CrossRef]

30) Kieselbach T, Armgarth E, Bagnara S, Elo AL, Jefferys S, Joling C, Kuhn K, Nielsen K, Popma J, Rogovsky N, Sahler B, Thomson G, Triomphe CE, Widerszal-Bazyl M (2009) Health in restructuring: innovative approaches and policy recommendations, München-Mering, Hampp.

31) Nielsen K, Randall R (2012) The importance of employee participation and perceptions of changes in procedures in a teamworking intervention. Work Stress 26, 91-111. [Medline] [CrossRef]

32) Nytrø K, Saksvik PØ, Mikkelsen A, Bohle P, Quinland M (2000) An appraisal of key factors in the implementation of occupational stress interventions. Work Stress 14, 213-25. [CrossRef]

33) Saksvik PØ, Tvedt SD, Nytrø K, Andersen GR, Andersen TK, Buvik MP, Torvant H (2007) Developing criteria for healthy organizational change. Work Stress 21, 243-63. [CrossRef]

34) Sørensen O, Hasle P (2009) The importance of trust in organizational change. In: Saksvik P (Eds.), Prerequisites for Healthy Organizational Change 10-29, Bentham Science Publisher Ltd.

35) Elinkeinoelämän keskusliitto (2006) Työaikakatsaus: Työajat ja poissaolot EK:n jäsenyrityksissä vuonna 2006 [Working time and sickness absences in member organizations of EK in 2006]. http://www.ek.fi/ek/fi/ tutkimukset_julkaisut/arkisto/2007/Tyoaikakatsaus.pdf.

36) Pahkin K, Leppänen A, Kajosaari K, Ala-Laurinaho A, Welling I, Väänänen A, Joensuu M, Koskinen A (2010) Työhyvinvoinnin kehittäminen ja sairauspoissaolojen hallinta paperiteollisuudessa [Developing well-being and managing sickness absencies in the paper industry], Työympäristötutkimuksen raporttisarja 48, Työterveyslaitos, Helsinki.

37) Paperiliitto (2009) Kysely osastojen luottamusmiehille 2009 [Survey to the elected official of departments], Helsinki, Paperiliitto.

38) Cohen SG (1994) Designing effective self-managing work teams. In: Beyerlein MM and Johnson DA (Eds.), Advances in interdisciplinary studies of work teams: Theories of selfmanaging work teams. Vol. I, 67-102, JAI Press, Stanford.

39) Moyle P (1998) Longitudinal influence of managerial support on employee well-being. Work Stress 12, 29-49. [CrossRef] 
40) Elo AL, Leppänen A, Lindström K, Ropponen T (1992) OSQ. Occupational stress questionnaire: user's instructions, Finnish Institute of Occupational Health, Helsinki.

41) Elo AL (1994) Assessment of mental stress factors at work. In: ZenzC, Dickerson OB and Howarth EP (Eds.), Occupational Medicine, 945-959, Mosby, Baltimore.

42) Elo AL, Leppänen A, Jahkola A (2003) Validity of a singleitem measure of stress symptoms. Scand J Work Environ Health 29, 444-51. [Medline] [CrossRef]

43) Widmer PS, Semmer NK, Kälin W, Jacobshagen N, Meier LL (2012) The ambivalence of challenge stressors: time pressure associated with both negative and positive wellbeing. J Vocat Behav 80, 422-33. [CrossRef]

44) Wanous JP, Reichers AE, Hudy MJ (1997) Overall job satisfaction: how good are single-item measures? J Appl Psychol 82, 247-52. [Medline] [CrossRef]

45) Schaufeli WB, Salanova M, Gonzalez-Roma V, Bakker AB (2002) The measurement of engagement and burnout: a two sample confirmatory factor analytic approach. J Happiness Stud 3, 71-92. [CrossRef]

46) Lazarus RS (1993) From psychological stress to the emotions: a history of changing outlooks. Annu Rev Psychol 44, 1-21. [Medline] [CrossRef]

47) Nielsen K, Randall R, Holten AL, Rial González E (2010) Conducting organizational-level occupational health interventios: what works? Work Stress 24, 234-59. [CrossRef]

48) Väänänen A, Pahkin K, Kalimo R, Buunk BP (2004) Maintenance of subjective health during a merger: the role of experienced change and pre-merger social support at work in white- and blue-collar workers. Soc Sci Med 58, 1903-15. [Medline] [CrossRef]

49) Swanson V, Power K (2001) Employees' perceptions of organizational restructuring: the role of social support. Work Stress 15, 161-78. [CrossRef]
50) Daniels K, Boocock G, Glover J, Holland J, Hartley R (2009) An experience sampling study of learning, affect, and the demands control support model. J Appl Psychol 94, 1003-17. [Medline] [CrossRef]

51) Weinberg A, Cooper C (2012) Stress in turbulent times, Palgrave Macmillan, Hampshire.

52) LePine JA, Podsakoff NP, LePine MA (2005) A metaanalytic test of the challenge stressor-hindrance stressor framework: an explanation for inconsistent relationships among stressors and performance. Acad Manage J 48, 764-75. [CrossRef]

53) Checkoway H, Pearce N, Dement JM (1989) Design and conduct of occupational epidemiology studies: I. Design aspects of cohort studies. Am J Ind Med 15, 363-73. [Medline] [CrossRef]

54) Tvedt S, Saksvik P, Nytrø K (2009) Does change process healthiness reduce the negative effects of organizational change on the psychosocial work environment? Work Stress 23, 80-98. [CrossRef]

55) Pahkin K, Mattila-Holappa $P$, Väänänen A, Koskinen A, Nielsen K (2013) Dismissals - a major concern, but only one among others? Ind Health 51, 134-41. [Medline] [CrossRef]

56) Demerouti E, Bakker AB, Nachreiner F, Schaufeli WB (2001) The job demands-resources model of burnout. J Appl Psychol 86, 499-512. [Medline] [CrossRef]

57) Bakker AB, Demerouti E (2007) The Job demandsResources model: state of the art. J Manag Psychol 22, 309-28.

58) van den Heuvel M, Demerouti E, Bakker A, Schaufeli W (2013) Adapting to change: the value of change information and meaning-making. J Vocat Behav 83, 11-21. [CrossRef]

59) Hakanen JJ, Koivumäki J (2014) Engaged or exhaustedHow does it affect dentists' clinical productivity? Burnout Research, http:dx.doi.org/10.1016/j.burn.2014.02.002. 